\title{
Reservoir Sedimentation Based on Uncertainty Analysis
}

\author{
Farhad Imanshoar, ${ }^{1}$ Afshin Jahangirzadeh, ${ }^{2}$ Hossein Basser, ${ }^{2}$ Shatirah Akib, ${ }^{2}$ \\ Babak Kamali, ${ }^{2}$ Mohammad Reza M. Tabatabaei, ${ }^{3}$ and Masoud Kakouei ${ }^{4}$ \\ ${ }^{1}$ Faculty of Civil Engineering, University of Tabriz, Tabriz, Iran \\ ${ }^{2}$ Department of Civil Engineering, Faculty of Engineering, University of Malaya, 50603 Kuala Lumpur, Malaysia \\ ${ }^{3}$ Faculty of Water and Environment Engineering, Power and Water University of Technology, Tehran, Iran \\ ${ }^{4}$ Department of Computer Engineering, Faculty of Engineering, Payam Noor University, Astaneh Ashrafieh, Iran
}

Correspondence should be addressed to Afshin Jahangirzadeh; afshin.jk@gmail.com

Received 16 September 2013; Revised 23 January 2014; Accepted 27 January 2014; Published 4 March 2014

Academic Editor: Mohamed Fathy El-Amin

Copyright (C) 2014 Farhad Imanshoar et al. This is an open access article distributed under the Creative Commons Attribution License, which permits unrestricted use, distribution, and reproduction in any medium, provided the original work is properly cited.

\begin{abstract}
Reservoir sedimentation can result in loss of much needed reservoir storage capacity, reducing the useful life of dams. Thus, sufficient sediment storage capacity should be provided for the reservoir design stage to ensure that sediment accumulation will not impair the functioning of the reservoir during the useful operational-economic life of the project. However, an important issue to consider when estimating reservoir sedimentation and accumulation is the uncertainty involved in reservoir sedimentation. In this paper, the basic factors influencing the density of sediments deposited in reservoirs are discussed, and uncertainties in reservoir sedimentation have been determined using the Delta method. Further, Kenny Reservoir in the White River Basin in northwestern Colorado was selected to determine the density of deposits in the reservoir and the coefficient of variation. The results of this investigation have indicated that by using the Delta method in the case of Kenny Reservoir, the uncertainty regarding accumulated sediment density, expressed by the coefficient of variation for a period of 50 years of reservoir operation, could be reduced to about $10 \%$. Results of the Delta method suggest an applicable approach for dead storage planning via interfacing with uncertainties associated with reservoir sedimentation.
\end{abstract}

\section{Introduction}

Reservoir sedimentation is filling of the reservoir with sediment carried into the dam reservoir by streams [1]. Understanding the reservoir sedimentation process is of fundamental significance in hydrosystems engineering. Sediment inflow and deposition can affect the function of dam reservoirs. Therefore, it is of crucial importance to estimate the sedimentation rate and the period of time before sediment accumulation could interfere with the useful functioning of the reservoir. When designing a reservoir, sufficient sediment storage capacity should be taken into account so that sediment accumulation will not impair the function of the reservoir during the useful operational-economic life of the project [2].

Sedimentation process in a reservoir is quite complex because it is often influenced by several factors including hydrological fluctuations in water and sediment inflow, variation in sediment particle size, reservoir operation cycle, and physical controls such as size and shape of the reservoir $[3,4]$. Other factors that may be important for some reservoirs are vegetation cover in upper reaches, turbulence and density currents, erosion of deposited sediments, and sluicing of sediment through the dam.

Once the volume of sediment inflow to a reservoir has been determined, effects of the sedimentation process over the life span and the daily operation of the reservoir must be evaluated. In the design of a reservoir, the mean annual sediment inflow, the efficacy of the reservoir in trapping sediment, the ultimate density of the deposited sediment, and the distribution of the sediment within the reservoir are among the most important factors that must be considered. Additional storage volume equal to the volume of the sediment expected to be deposited during the life of the reservoir is often included in the original design to prevent premature loss of storage capacity. The United States Bureau of Reclamation [2] suggests using a 100-year period of 
economic analysis and sediment accumulation in a reservoir. Less than 100 years of sediment accumulation may also be suggested in cases where the economic analysis justifies lesser allocation. However, there is uncertainty associated with the factors involved in reservoir sedimentation. The sources of uncertainty can be generally classified into two main groups: first group is natural factors (the natural factors are related to natural happenings and conditions), which include meteoric factors, changes in watershed hydraulic characteristics, and natural disaster occurrences. Second group is unnatural factors (the unnatural factors are caused by human-induced activities) which include land-use changes and management strategies $[3,4]$.

On the whole, natural variability and model related uncertainties constantly have an effective role in accuracy of determining the amount of sediment deposition in the reservoir on a yearly basis, the accumulated sediment volume in the reservoir over the number of years of reservoir operation, and the time it takes for the accumulation of a certain amount of sediment in the reservoir (e.g., a fraction of the death capacity or a fraction of the total capacity of the reservoir) $[3,5,6]$. In this context, the response of the system to variable, uncertain inputs can be statistically quantified through uncertainty analysis [7].

Salas and Shin [3] analyzed the uncertainty of many factors involved in reservoir sedimentation. These factors, called "stochastic inputs," include those inputs associated with annual suspended and bed load sediment rating curves, those associated with the type of incoming sediment, those associated with the trap efficacy of a reservoir, and those associated with the variability of annual stream flow. Intrinsically, these inputs are of random phenomena $[7,8]$. This type of variability is always associated with the factors involved in reservoir sedimentation and may not be controlled $[3,9]$.

This study focuses on identifying the basic factors influencing the density of sediments deposited in the reservoirs and determining uncertainties in reservoir sedimentation using the Delta method. A case study of Kenny Reservoir in the White River Basin in northwestern Colorado [3, 9] was designated to determine the density of deposits in the reservoir and the coefficient of variation. Thus, the present study is an attempt to ascertain the accuracy of determining the mean density of accumulated sediments after a certain period of time by calculating the coefficient of variation [9].

\section{Factors Contributing to Reservoir Sedimentation}

2.1. Natural Factors. Natural factors affecting reservoir sedimentation are those intrinsic aspects of the world's water hydrologic cycle and the rate of land surface change. These factors are meteoric factors (e.g., precipitation, snow, hail, and wind) [3], watershed topography and geology, vegetation cover, natural disasters (e.g., floods and droughts), and the hydraulic condition of the reservoir (e.g., the ratio of reservoir capacity to inflow volume, the shape of the reservoir, specifications of bottom outlets, the condition of reservoir
TABLE 1: Sediment classification according to size.

\begin{tabular}{lc}
\hline Sediment type & Size range $(\mathrm{mm})$ \\
\hline Clay & $<0.004$ \\
Silt & 0.004 to 0.062 \\
Sand & 0.062 to 2 \\
\hline
\end{tabular}

operation, the trap efficiency of the reservoir, flow turbulence, and physical properties of inflow) [11].

2.2. Unnatural (Human-Induced) Factors. Overexploitation of forests, destruction of grasslands, and land-use changes induced by human activities affect water resources and often intensify soil erosion which consequently increase reservoir sedimentation rates in different ways. Management strategies, as a human-related factor, can also directly affect the sedimentation process in reservoir dams. The main deficiencies in this field could be the propensity to store water from wet to dry seasons, the tendency to produce more hydropower energy without considering sedimentary aspects, incorrect design of water works, and shortcomings of operation manuals [11, 12].

\section{Methods}

3.1. Density of Deposited Sediments. Basic factors influencing the density of sediments deposited in a reservoir are (i) the reservoir operation and management, (ii) the texture and size of deposited sediment particles, and (iii) the compaction or consolidation rate of deposited sediments [2, 11]. Among these, the operational plan of the reservoir is probably the most significant factor $[2,3,5]$. Sediments deposited in a reservoir are subject to considerable drawdown with the result that the sediments may be exposed for long periods, and therefore undergo greater consolidation. On the other hand, reservoirs which operate under a fairly stable pool do not allow the deposits to dry out and consolidate as much. The size of the incoming sediment particles has a significant effect on density of deposits. Sediment deposits composed of silt and sand have higher densities than those in which clay predominates [2]. The classification of sediments according to size is proposed by the American Geophysical Union (Table 1).

Accumulation of new sediment deposits on top of previously deposited sediments often changes the density of earlier deposits. The consolidation process affects the average density over the estimated life of the reservoir, such as for a 100-year period. Therefore, the influence of reservoir operation is the most significant factor due to its effect on the amount of consolidation that can take place in the clay fraction of the deposited material when a reservoir is subject to considerable drawdown. Strand and Pemberton [10] classified reservoir operations (Table 2).

Abovementioned reservoir types for operation were assessed by engineering judgment. Selection of the proper reservoir operation can usually be made through the operation study prepared for the reservoir [10]. This concept 
TABLE 2: Classification of reservoir operation [10].

\begin{tabular}{ll}
\hline No. & Reservoir operation \\
\hline 1 & Sediment always submerged or nearly submerged \\
2 & $\begin{array}{l}\text { Normally moderate to considerable reservoir } \\
\text { drawdown }\end{array}$ \\
3 & Reservoir normally empty \\
4 & Riverbed sediments \\
\hline
\end{tabular}

depends on hydraulic conditions of the intake and sediment trap coefficient of the reservoir. For example, for reservoir type 1, released water of dam is clear or near to clear; therefore the sediments are always submerged or nearly submerged while for reservoir type 4, running river flow passes the dam and, in other words, the released water is debris flow. The other two operations are judged in this manner.

The size of sediment particles entering the reservoir also affects the density, as shown by the variation in initial masses. Once the reservoir operation number has been assessed, the density of the sediment deposits can be estimated using (1) $[2,10]$. Consider

$$
W_{0}=W_{C} P_{C}+W_{m} P_{m}+W_{S} P_{S},
$$

where $W_{0}$ is unit weight $\left(\mathrm{kg} / \mathrm{m}^{3}\right), P_{C}, P_{m}$, and $P_{S}$ are the percentages of clay, silt, and sand in the inflowing sediment, respectively, and $W_{C}, W_{m}$, and $W_{S}$ are coefficients of unit weight of clay, silt, and sand, respectively (Table 3) $[2,10]$.

Sediments accumulate in the reservoir in each of the $T$ years of operation, and each year's deposit will have a different compaction time, which is significantly dependent on the type of reservoir operation and the size of the incoming sediment particles. Thus, density of sediments deposited during $T$ years of reservoir operation can be estimated as an approximation of the integral of $(2)[5,13]$ :

$$
W_{T}=W_{0}+0.4343 K\left[\frac{T}{T-1}(\ln T)-1\right], \quad T>1,
$$

where $W_{T}$ is the average density after $T$ years of operation, $W_{0}$ is the initial unit weight (density) derived from (1), and $K$ is consolidation constant dependent on type of reservoir operation and sediment size distribution (Table 4). In practice, a weighted average of consolidation constants must be used for a mixture of sediment $(3)[2,5,13]$ :

$$
K_{i}=K_{C} P_{C}+K_{m} P_{m}+K_{S} P_{S} .
$$

\subsection{Analysis of Uncertainty of Reservoir Sedimentation.} When designing hydrosystems, it is essential to take uncertainty into consideration since many influences are functionally related to a number of uncertain variables. For instance, as already noted, natural factors and unnatural factors result in a complex and uncertain procedure for reservoir sedimentation trend, and hence sediment density is subject to uncertainty. On the other hand, optimal design of reservoir geometry (dead storage and live storage) is a fundamental goal for hydraulic engineers.
TABLE 3: Initial unit weight of incoming sediments based on reservoir operation and type of sediments.

\begin{tabular}{lccc}
\hline $\begin{array}{l}\text { Operation } \\
\text { type }\end{array}$ & \multicolumn{3}{c}{ Initial unit weight $\left(\mathrm{kg} / \mathrm{m}^{3}\right)$} \\
\hline 1 & Clay- $W_{C}$ & Silt- $W_{m}$ & Sand- $W_{S}$ \\
2 & 416 & 1120 & 1550 \\
3 & 561 & 1140 & 1550 \\
4 & 641 & 1150 & 1550 \\
\hline
\end{tabular}

TABLE 4: $K$ values for incoming sediments based on reservoir operation and type of sediment [2].

\begin{tabular}{lccc}
\hline $\begin{array}{l}\text { Operation } \\
\text { type }\end{array}$ & Clay- $K_{C}$ & $\begin{array}{c}K \text { values for SI units } \\
\text { Silt- } K_{m}\end{array}$ & Sand- $K_{S}$ \\
\hline 1 & 256 & 91 & 0 \\
2 & 135 & 29 & 0 \\
3,4 & 0 & 0 & 0 \\
\hline
\end{tabular}

Several methods for uncertainty analysis have been developed and applied in water resources engineering. The most widely used methods are Monte Carlo Simulation (MCS) and first-order analysis (FOA) $[3,5]$. The latter is based on linearization of the functional relationship which relates a dependent random variable and a set of independent random variables by Taylor series expansion. The FOA method has been applied to several water resource and environmental engineering problems including uncertainty $[5,6,14]$. For example, Tehrani et al. benefited from Latin Hypercube Sampling method to estimate accumulated reservoir sediment volume in Shahr-Chai Dam by FOA method and the sensitivity analysis showed that suspended sediment and bed load, followed by annual stream flow, were the most important factors influencing the accumulated reservoir sedimentation volume, for both the total period and the wet and dry time periods, and trap efficiency and percentage of sediments are the next most important [5]. Furthermore, Hall used FOA method to extend a fuzzy set theory and possibility theory for coastal hydraulics [14].

In MCS method, stochastic inputs are generated from their probability distributions and are then entered into empirical or analytical models of the underlying physical process involved in generating stochastic outputs. The generated outputs are then analyzed statistically to quantify the uncertainty of the output $[15,16]$. Salas and Shin [3] analyzed the uncertainty of annual reservoir sedimentation volume (RSV) and accumulated reservoir sedimentation volume (ARSV) based on Monte Carlo Simulation (MCS) and Latin Hypercube Sampling (LHS). The procedures were applied to the case of Kenny Reservoir in the White River basin in Colorado. The results indicated that the variability of RSV may be described by a Gamma-2 distribution for which the coefficient of variation was of the order of $65 \%$ [3]. This rate of variation for determining annual reservoir sedimentation volume makes a serious challenge to design or manage the reservoir operation. 
Although the abovementioned studies developed methodical outcomes in hydrosystem analysis especially in alluvial hydraulics uncertainties, in these researches the density of sediments which were deposited in the reservoir was assumed constant. The sediments, which accumulate in the reservoir by passing the time, will have a different compaction; therefore their density will change depending on variety of factors. Consequently, in this paper in order to develop former studies, it is aimed to focus on identifying the basic factors which affect the density of sediments deposited in the reservoirs. Also uncertainties in reservoir sediments density are determined using the Delta method.

3.3. Analysis of Uncertainty (Delta Method). First-order analysis of uncertainties, which is also known as the Delta method, is a rather straightforward and useful technique for the approximation of such uncertainties. This method is widely used in many fields of engineering due mainly to its ease of application to a wide variety of problems [17-19]. Mays stated that Delta method application is quite popular in many fields of engineering and, as a result, he developed a risk-based solution for storm sewers' design [17]. Imanshoar et al. used Delta method to study trophic state index (TSI) uncertainty and its variation for Miyun Reservoir in China. Their research showed that the average TSI number and its variation for mentioned reservoir oscillated between Mesotrophic to Eutrophic category [18]. Furthermore, Resende et al. applied Delta method to estimate the mapping, from uncertainty in discrete choice model parameters to uncertainty of profit outcomes, and they identified the estimated $\alpha$-profit as a closed form function of design decision variables in computer science [19].

First-order analysis is often used to assess the uncertainty in a deterministic model formulation involving parameters which are uncertain (i.e., not known with certainty). Firstorder analysis specifically enables us to determine the mean and variance of a random variable which is functionally related to several other variables, some of which are random. Thus, using first-order analysis, the combined effect of uncertainty in a model formulation, and the use of uncertain parameters can be assessed [14, 17]. Consider a random variable $y$ that is a function of $k$ random variables (4) (multivariate case) [17]:

$$
y=G\left(x_{1}, x_{2}, \ldots, x_{j}\right)=G\left(x_{i}\right), \quad i=1 \sim j .
$$

This function can be expressed as a deterministic equation such as the equation mentioned above, a rational formula or Manning's equation, or a complex model that must be solved on a computer. The objective is to treat a deterministic model that has uncertain inputs in order to determine the effect of the uncertain parameters $x_{1}, \ldots, x_{k}$ on the model output $y$. Equation (4) can be expressed as $y=G\left(x_{i}\right)$, where $x=$ $x_{1}, x_{2}, \ldots, x_{k}$. Using a Taylor series expansion of $k$ random variables, ignoring the second and higher order terms, we can obtain [17]

$$
\mu_{y} \approx G(\bar{x})+\sum_{i=1}^{j}\left(\frac{\partial G}{\partial x_{i}}\right)_{\bar{x}}\left(x_{i}-\bar{x}_{i}\right),
$$

where $\mu_{y}$ refers to the mean value of $y$ under the variation of $x_{i}$ and the derivation $\left(\partial G / \partial x_{i}\right)_{\bar{x}}$ are the sensitivity coefficients that represent the rate of change of the function value $G\left(x_{i}\right)$ at $\left(x_{i}-\bar{x}_{i}\right)$. Assuming that the $k$ random variables are independent, the variance of $y$ can be approximated as [17]

$$
\Omega_{y}^{2}=\sum_{i=1}^{j}\left[\left(\frac{\partial G}{\partial x_{i}}\right)_{\bar{x}_{i}}^{2}\left(\frac{\bar{x}_{i}}{\mu_{y}}\right)^{2} \Omega_{x_{i}}^{2}\right] .
$$

It is important to remember that all of the random parameters are assumed to follow a uniform distribution, so the mean and variance of each parameter can be calculated using mean $=(a+b) / 2$ and variance $=(a-b)^{2} / 12$, in which $a$ and $b$ are the lower and upper bounds, respectively (7). Consider

$$
\Omega=\frac{\sigma}{\bar{X}}=\frac{\sqrt{3}}{3}\left(\frac{b-a}{b+a}\right) .
$$

3.3.1. Uncertainty Analysis for Density of Sediments Deposited. Notwithstanding the advances made in understanding several factors involved in reservoir sedimentation, predicting the accumulation of sediment in a reservoir throughout the years after construction of the dam is still a complex problem in hydraulic engineering. As noted earlier, the volume of reservoir sedimentation depends, among other factors, on the quantity of sediment inflow, the percentage of sediment inflow trapped by the reservoir, and the specific weight of the deposited sediments considering the effect of compaction with time. The sediments entering a reservoir are generally a mixture of clay, silt, and sand. The fraction of each type of sediment, namely, $P_{C}, P_{m}$, and $P_{S}$ (for clay, silt, and sand, resp.), vary from year to year. Thus, it would be impractical to determine such variable fractions from field measurements. Standard statistical analysis can offer a certain distribution function for predicting fractions of each sediment type. For instance, it may be assumed that such fractions are uniformly distributed with lower and upper bounds that are obtained from the measurements. Or the fractions of each type of sediments may be assumed to be independent. In this approach the percentages of clay, silt, and sand will have to be adjusted so that they add up to $100 \%$ [3].

Therefore, to determine the uncertainty associated with the type of incoming sediment and their effect on deposited sediment's density, (2) can be rewritten using (1) and (3) as follows:

$$
\begin{aligned}
W_{T}= & P_{C}\left\{W_{C}+0.434 K_{C}\left[\frac{T}{T-1}(\ln T)-1\right]\right\} \\
& +P_{m}\left\{W_{m}+0.434 K_{m}\left[\frac{T}{T-1}(\ln T)-1\right]\right\} \\
& +P_{S}\left\{W_{S}+0.434 K_{S}\left[\frac{T}{T-1}(\ln T)-1\right]\right\} .
\end{aligned}
$$


Using (5) and (6), the variation coefficient of deposited sediments' density after $T$ years of operation could be determined as follows:

$$
\begin{aligned}
\Omega_{W_{T}}^{2}= & \left(\frac{\partial W_{T}}{\partial P_{C}}\right)^{2}\left(\frac{\partial \bar{P}_{C}}{\partial \mu_{W_{T}}}\right)^{2} \Omega_{P_{C}}^{2}+\left(\frac{\partial W_{T}}{\partial P_{m}}\right)^{2}\left(\frac{\partial \bar{P}_{m}}{\partial \mu_{W_{T}}}\right)^{2} \Omega_{P_{S}}^{2} \\
& +\left(\frac{\partial W_{T}}{\partial P_{S}}\right)^{2}\left(\frac{\partial \bar{P}_{S}}{\partial \mu_{W_{T}}}\right)^{2} \Omega_{P_{S}}^{2}
\end{aligned}
$$

where $\Omega_{W_{T}}$ is the coefficient of variation of sediments' density after $T$ years of operation, and $\Omega_{P_{C}}, \Omega_{P_{m}}$, and $\Omega_{P_{S}}$ are the variation coefficient of clay, silt, and sand percentage, respectively. Equation (9) can thus be rewritten as follows:

$$
\begin{aligned}
\Omega_{W_{T}}^{2}= & \left(W_{C}+0.434 K_{C}\left[\frac{T}{T-1}(\ln T)-1\right]\right)^{2}\left(\frac{\partial \bar{P}_{C}}{\partial \mu_{W_{T}}}\right)^{2} \Omega_{P_{C}}^{2} \\
& +\left(W_{m}+0.434 K_{m}\left[\frac{T}{T-1}(\ln T)-1\right]\right)^{2}\left(\frac{\partial \bar{P}_{m}}{\partial \mu_{W_{T}}}\right)^{2} \Omega_{P_{S}}^{2} \\
& +\left(W_{S}+0.434 K_{S}\left[\frac{T}{T-1}(\ln T)-1\right]\right)^{2}\left(\frac{\partial \bar{P}_{S}}{\partial \mu_{W_{T}}}\right)^{2} \Omega_{P_{S}}^{2}
\end{aligned}
$$

\section{Results and Discussion}

4.1. Case Study (Kenny Reservoir). Uncertainty analysis of density of sediments deposited in reservoir after $T$ years of operation as described earlier was applied to the Kenny Reservoir in the White River Basin in northwestern Colorado. Taylor Draw Dam was constructed in the early 1980's and created the Kenny Reservoir with a capacity of about $17 \times$ $10^{6} \mathrm{~m}^{3}$, which has been in operation since $1984[3,20]$.

The mean density of sediments deposited after $T=50$ years of operation and its coefficient of variation for Kenny Reservoir data was determined using the abovementioned method. The range of percentages of each type of sediment (i.e., $P_{C}, P_{m}$, and $P_{S}$ for clay, silt, and sand, resp.) are independent because of their physical differences. It is important to mention that Tobin and Hollowed evaluated statistical distributions of each type of sediment and found them close to the uniform type, and therefore they assumed them to be uniformly distributed $[3,9]$. Also, according to the reservoir hydraulic condition (permanent reservoir with long length) the sediments were always submerged. Also, the lower and upper bounds for each fraction were analyzed by Tobin and Hollowed using twenty samples of suspended sediment which were collected $[3,9]$ (Table 5).

It should be borne in mind that for each sample the percentages of clay, silt, and sand should add up to $100 \%$ $\left(P_{C}+P_{m}+P_{S}=100 \%\right)$. The mean percentages of sediment accumulated (Table 5) can be summarized according to the type and the coefficient of variation using (9).

Assuming the sediments are always submerged or nearly submerged in Kenny Reservoir (using Table 6 and (8)), the
TABLE 5: Clay, silt, and sand percentages range.

\begin{tabular}{lccc}
\hline Sediment type & Lower bound & Upper bound & Distribution \\
\hline$P_{C}(\%)$ & 16 & 41 & Uniform \\
$P_{m}(\%)$ & 39 & 63 & Uniform \\
$P_{S}(\%)$ & 14 & 43 & Uniform \\
\hline
\end{tabular}

TABLE 6: Statistical properties of stochastic inputs for uncertainty analysis.

\begin{tabular}{lccc}
\hline Sediment type & Mean & $\begin{array}{c}\text { Standard } \\
\text { deviation }\end{array}$ & $\begin{array}{c}\text { Coefficient of } \\
\text { variation }\end{array}$ \\
\hline$P_{C}(\%)$ & 28.5 & 7.216884 & 0.253224 \\
$P_{m}(\%)$ & 51 & 6.928197 & 0.135847 \\
$P_{S}(\%)$ & 28.5 & 8.37159 & 0.293740 \\
\hline
\end{tabular}

mean density of sediments after $T=50$ years of operation can be obtained as follows:

$$
\begin{aligned}
\mu_{w_{T}}= & \frac{28.5}{100}\left\{416+0.4343 \times 256\left[\frac{50}{50-1}(\ln 50)-1\right]\right\} \\
& +\frac{51}{100}\left\{1120+0.4343 \times 91\left[\frac{50}{50-1}(\ln 50)-1\right]\right\} \\
& +\frac{28.5}{100}\{1500+0\}=1065.42 \mathrm{~kg} / \mathrm{m}^{3} .
\end{aligned}
$$

Then, using Table 4 (reservoir type 1) and (10), coefficient of variation of sediments' density after $T=50$ years of Kenny reservoir operation can be assessed as follows:

$$
\Omega_{W_{T}}^{2}=0.0098 \longrightarrow \Omega_{W_{T}}=0.099 .
$$

Hence, the accuracy in determining the mean density of sediments after $T=50$ years of operation in this reservoir is $\pm 9.9 \%$. Further, the standard deviation of this parameter can be determined as follows:

$$
\sigma_{W_{T}}=\mu_{W_{T}} \Omega_{W_{T}}
$$

Thus,

$$
\sigma_{W_{T}}=1065.42 \times 0.099=105.48 \mathrm{kgm}^{-3},
$$

where $\sigma_{W_{T}}$ refers to the standard deviation of variable $y$ (in this case $y=W_{T}$ ).

Results of this case study indicate that the mean density of sediments deposited after 50 years of operation in Kenny Reservoir is $1065.42 \pm 105.48$ (mean \pm SD) $\mathrm{kg} / \mathrm{m}^{3}$ (14). Therefore, the accuracy of calculating the mean density of sediments deposited after the 50th year of operation and the needed volume for dead storage design is $9.9 \%(\sim 10 \%)$.

\section{Conclusion}

Due to the wide range of uncertain parameters involved in the design procedure, predicting the deposition and accumulation of sediments in a reservoir is a complex problem, 
one that has attracted the attention of hydraulic engineers and scientists for many decades. In this paper, the problem of analyzing and quantifying the uncertainty of mean density of sediments deposited in a reservoir and its compaction through the years of reservoir operation has been addressed.

Since in previous studies the density of sediments which were deposited in the reservoir were assumed constant, in this paper the former studies were developed by identifying the basic factors which affect the density of sediments deposited in the reservoirs. Also uncertainties in reservoir sediments density are determined using the Delta method.

For this purpose, the uncertainty of the input factors (stochastic inputs) was analyzed first. Then, using the Delta method, the uncertainty associated with the type of incoming sediments and their effect on density of sediments and its coefficient of variation were determined.

Results of this research indicate that the mean density of sediments deposited after 50 years of operation in Kenny Reservoir is $1065.42 \pm 105.48$ (mean \pm SD) $\mathrm{kg} / \mathrm{m}^{3}$. Therefore, the accuracy of calculating the mean density of sediments deposited after the 50th year of operation and the needed volume for dead storage design is $10 \%$. This user-friendly method can be applied to engineering practices to optimize dead storage planning via interfacing with uncertainties associated with reservoir sedimentation.

\section{Conflict of Interests}

The authors declare that there is no conflict of interests regarding the publication of this paper.

\section{Acknowledgments}

Financial support by the high impact research grants of the University of Malaya (UM.C/625/1/HIR/116, account number: J-16002-00-7383000-000000) and (UM.C/625/1/HIR/ 61, account number: H-16001-00-D000061) is gratefully acknowledged. Also authors would like to thank the partly support of IPPP grant, number PV058-2012A.

\section{References}

[1] F. Imanshoar, Y. Hassanzadeh, M. T. Aalami, and A. Danandehmehr, "Uncertainty analysis for determining density of deposits in dams' reservoirs," Journal of Water and Soil Science, vol. 23, pp. 27-38, 2013 (Persian).

[2] United States Bureau of Reclamation (USBR), Design of Small Dams, United States Bureau of Reclamation (USBR), Denver, Colo, USA, 3rd edition, 1987.

[3] J. D. Salas and H. Shin, "Uncertainty analysis of reservoir sedimentation," Journal of Hydraulic Engineering, vol. 125, no. 4, pp. 339-350, 1999.

[4] S. W. Fleming, A. Marsh Lavenue, A. H. Aly, and A. Adams, "Practical applications of spectral analysis of hydrologic time series," Hydrological Processes, vol. 16, no. 2, pp. 565-574, 2002.

[5] M. V. Tehrani, J. M. V. Samani, and M. Montaseri, "Uncertainty analysis of reservoir sedimentation using Latin Hypercube sampling and Harr's method: Shahar Chai Dam in Iran," Journal of Hydrology New Zealand, vol. 47, no. 1, pp. 25-42, 2008.
[6] Y. K. Tung and B. C. Yen, Hydrosystems Engineering Uncertainty Analysis, McGraw-Hill, New York, NY, USA, 2005.

[7] S. Franceschini and C. W. Tsai, "Assessment of uncertainty sources in water quality modeling in the Niagara River," Advances in Water Resources, vol. 33, no. 4, pp. 493-503, 2010.

[8] O. O. Osidele, W. Zeng, and M. B. Beck, "Coping with uncertainty: a case study in sediment transport and nutrient load analysis," Journal of Water Resources Planning and Management, vol. 129, no. 4, pp. 345-355, 2003.

[9] R. L. Tobin and C. P. Hollowed, "Water quality and sediment transport Characteristics in Kenney reservoir, White river basin," Northwestern Colorado Report, U.S. Geological Survey, Denver, Colo, USA, 1990.

[10] R. I. Strand and E. L. Pemberton, "Reservoir sedimentation," Technical Guideline for Bureau of Reclamation, U.S. Department of Interior Bureau of Reclamation, Denver, Colo, USA, 1982.

[11] G. L. Morris and J. Fan, Reservoir Sedimentation Handbook: Design and Management of Dams, Reservoirs and Watersheds for Sustainable Use, McGraw-Hill, New York, NY, USA, 1997.

[12] V. Jothiprakash and V. Garg, "Re-look to conventional techniques for trapping efficiency estimation of a reservoir," International Journal of Sediment Research, vol. 23, no. 1, pp. 76-84, 2008.

[13] C. R. Miller, Determination of the Unit Weight of Sediment for Use in Sediment Volume Computations, U.S. Department of Interior Bureau of Reclamation, Denver, Colo, USA, 1953.

[14] J. W. Hall, "Handling uncertainty in the hydroinformatic process," Journal of Hydroinformatics, vol. 5, pp. 215-232, 2003.

[15] J. D. Salas, Analysis and Modelling of Hydrologic Time Series, McGraw-Hill, New York, NY, USA, 1993.

[16] J. M. V. Samani, M. Tehrani, and M. Montaseri, “The evaluation of three methods of uncertainty (MCS, LHS and Harr) in dam reservoir sedimentation," Journal of Engineering and Applied Sciences, vol. 2, pp. 1074-1084, 2007.

[17] L. W. Mays, Water Resources Engineering, John Wiley \& Sons, New York, NY, USA, 2nd edition, 2005.

[18] F. Imanshoar, Y. Hassanzadeh, and M. R. M. Tabatabai, "Analysis of trophic state uncertainty and its Variation: Miyun Reservoir, Beijing, China," in Proceedings of the 1st International Conference on Dams \& Hydropower (ICDHP '12), Tehran, Iran, February 2012.

[19] C. B. Resende, C. G. Heckmann, and J. J. Michalek, "Robust design for profit maximization under uncertainty of consumer choice model parameters using Delta method," in Proceedings of the ASME, 2011 International Design Engineering Technical Conferences \& Computers and Information in Engineering Conference, Washington, DC, USA, 2011.

[20] H. L. Chen, Stochastic characteristics of environmental and hydrologic time series [dissertation], Purdue University, Stillwater, Okla, USA, 1999. 


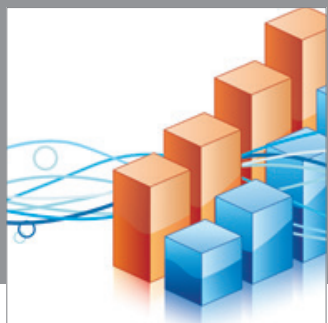

Advances in

Operations Research

mansans

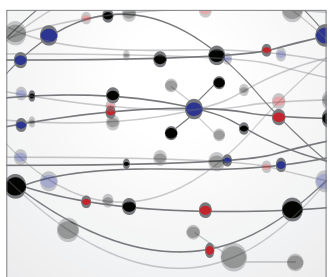

The Scientific World Journal
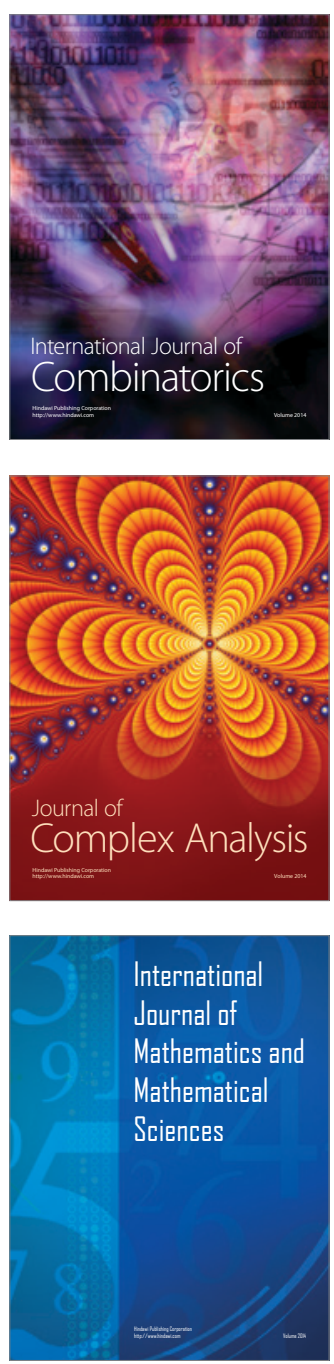
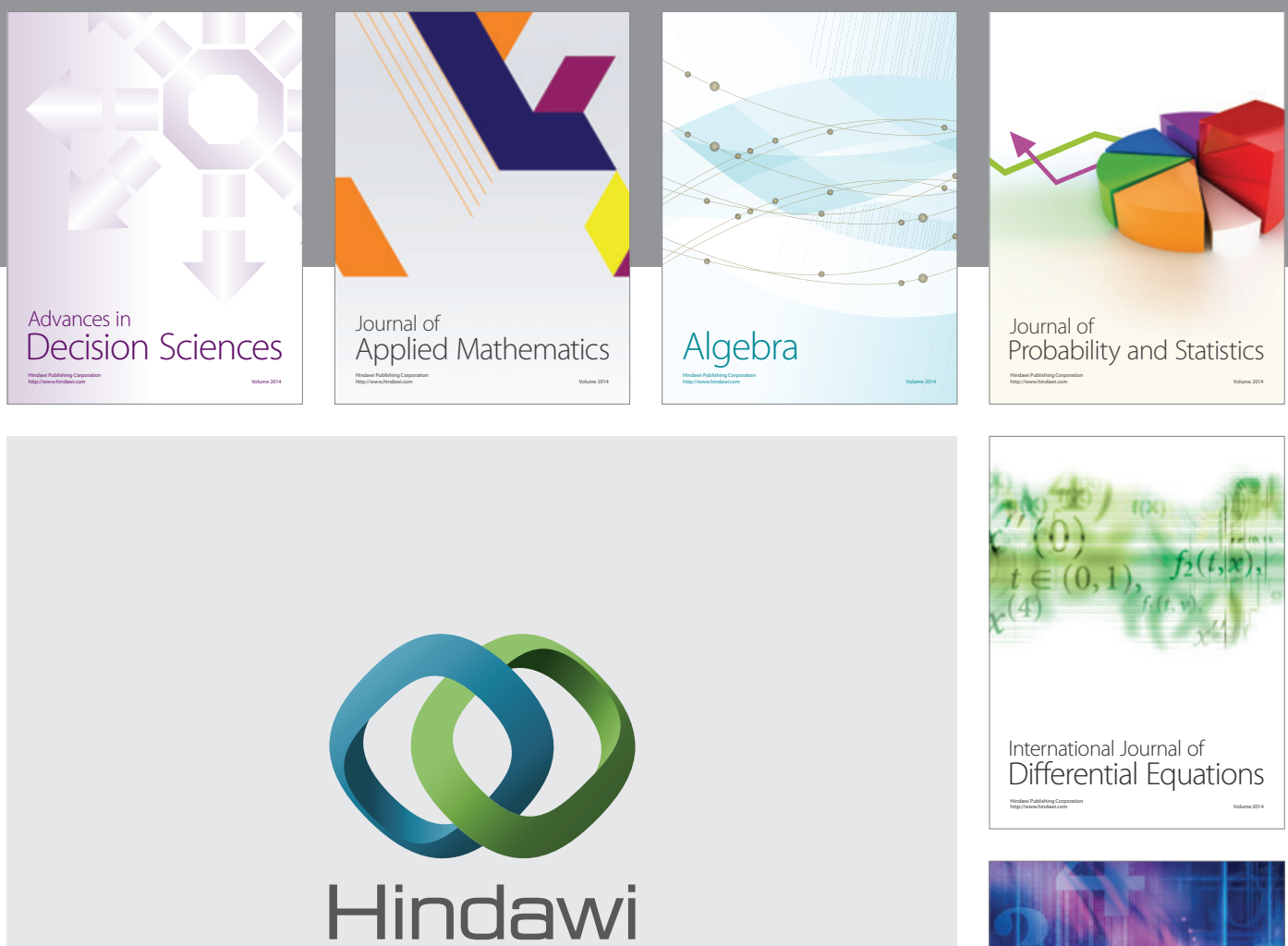

Submit your manuscripts at http://www.hindawi.com
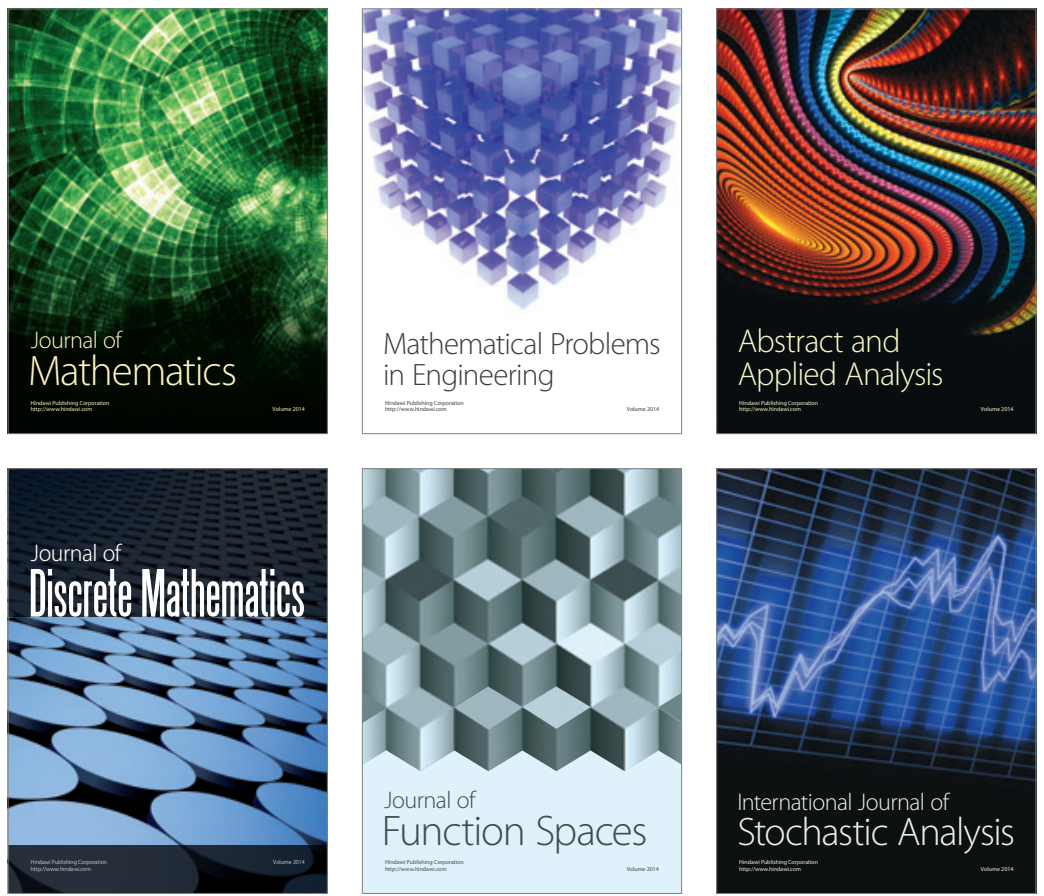

Journal of

Function Spaces

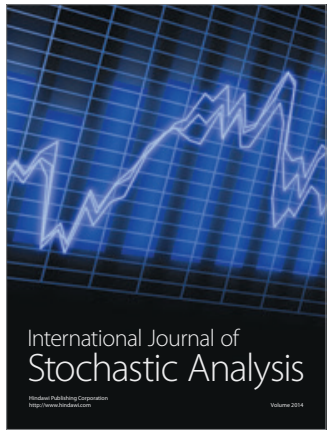

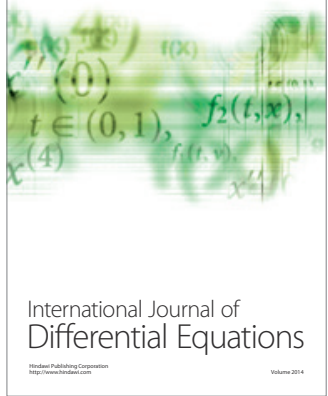
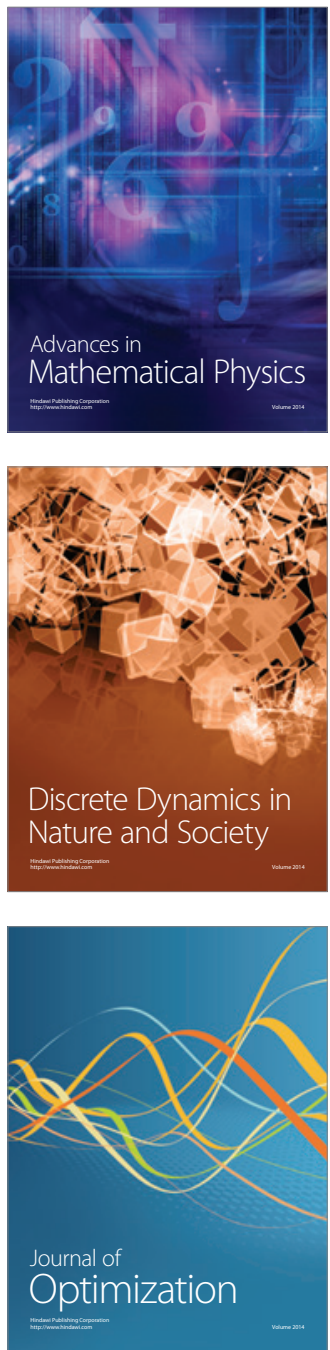